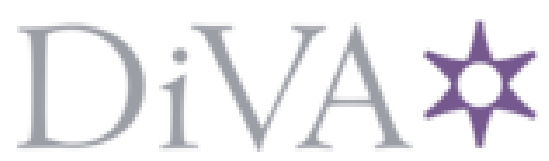

http://www.diva-portal.org

\title{
Postprint
}

This is the accepted version of a paper published in Social Responsibility Journal. This paper has been peer-reviewed but does not include the final publisher proof-corrections or journal pagination.

Citation for the original published paper (version of record):

Blombäck, A., Wigren-Kristoferson, C. (2014)

Corporate community responsibility as an outcome of individual embeddedness.

Social Responsibility Journal, 10(2): 297-315

Access to the published version may require subscription.

N.B. When citing this work, cite the original published paper.

Permanent link to this version:

http://urn.kb.se/resolve?urn=urn:nbn:se:hj:diva-24270 


\section{Corporate community responsibility as an outcome of individual embeddedness}

Paper accepted for publication in Social Responsibility Journal.

To cite:

Blombäck, A. and Wigren.-Kristoferson, C. (In-Press). "Corporate community relations as an outcome of individual embeddedness". Social Responsibility Journal, Vol. XX, No. XX.

\section{Introduction}

Corporate social responsibility (CSR) is an ever-present topic in academia, politics, and the media (Burton and Goldsby 2009; Commission of the European Communities 2001; Margolis and Walsh 2003; Valor 2005). A universal definition of CSR is hard to come by (Longo, Mura, and Bonoli 2005). Essentially, though, CSR implies companies' attention to the creation of a sustainable society and, consequently, responsibility for issues beyond profit maximization, like the environment, fair trade, and the local community. A recurring focus of the research in the area concerns the knowledge of the motivation behind CSR and the factors that can explain its development (Aguilera, Rupp, Williams and Ganapathi 2007). On that note, valuable insights can be drawn from organization studies, which accentuate that a firm's behaviour is related to its culture and that, to understand this, it is necessary to contemplate the organization's embeddedness in its surroundings (Wigren 2003). The notion of the embeddedness of firms 'puts the searchlight on the fact that any business activity reflects a complex socio-economic phenomenon' (Johannison, Ramírez-Pasillas, and Karlsson 2002, 298). Companies and their economic activities are influ- 
enced by business networks and by ties to social organizations and institutions, in which they encounter alternative motives and logics (Johannisson and Mønsted 1997).

Based on previous research and observations in rural SMEs, we propose that the available CSR constructs do not sufficiently capture the importance of individuals and the interpersonal relations in which organizations are embedded, particularly in regard to corporate community responsibility. In the light of embeddedness and interpretative accounting theories, we present four empirical stories to support our arguments and add to the ongoing and theoretical CSR discourse.

\section{Gaps in focus}

Perhaps the most popular outline of CSR is the three-domain construct presented by Schwartz and Carroll (2003). It conceptualizes CSR as the legal, economic, and ethical domains, and, as a result of the overlapping of domains, typifies seven categories of CSR. The three dimensions reflect that CSR is not only related to social welfare issues, which might be inferred from the inclusion of 'social', but rather considers firms' 'societal' responsibility (Andriof and McIntosh 2001; Whitehouse 2006). The construct approaches CSR as a firm-level practice and 'is especially useful for analyses that focus on the forces that come into play in ethical decision making [...]' (Schwartz and Carroll 2003, 513). In this respect, the three-domain outline is clearly tied to the understanding of firm behaviour as an outcome of multiple and complex social and economic interactions. It essentially neglects, though, the individuals involved, their interplay with the surrounding culture, and how this can create additional dimensions of accountability, which impact on the decisions taken in regard to CSR. Similarly, research on the topic often takes a macro/industry approach (Bertels and Peloza 2008; Griffin and Mahon 1997; Moore 2001; Sweeney and Coughlan 2008) or focuses on the meso/company level (Makni, Francoeur, and Bellavance 
2009; Preuss 2009). That is, researchers tend to view the business organization as the actor of primary interest. Treating organizations as conscious moral agents can be problematic, however, especially if it means losing sight of individual sense-making and the interaction between individuals (Ashman and Winstanley 2007). Few studies so far have taken the individuals' point of view to consider how they influence and are influenced by CSR and there is a need to move "beyond the personification of the corporation' (cf. Ashman and Winstanley 2007; Balmer, Fukukawa, and Gray 2007b; Hemingway and Maclagan 2004) and focus on the individual actor. Some scholars do emphasize the importance of individuals for CSR outcomes and processes, and more research is called for (Burton and Goldsby 2009; Hemingway and Maclagan 2004; Marz, Powers, and Queisser 2003). Aguilera et al. (2007) specifically outline a research model that takes into account the individual as an important level of analysis for understanding CSR. It portrays the potential impact of individual employees' need for control, belongingness, and meaning on the level of CSR, and how individual managers with enough power can influence organizations' CSR practices.

The discourse on corporate responsibility distinguishes between global and local citizenship (Logsdon and Wood 2002). The former focuses on the challenges and demands related to social, financial, and environmental concerns on a global scale and the latter on companies' relations to the local communities that directly surround their operations. This article concentrates on corporate community relations, including 'all the activities that promote the interests of the company and the communities where it is located' (Altman 1999, 46). The outline of CSR as 'local' indicates how firms experience accountability in the communities in which they operate and how, as a consequence, they seek to operate and act in ways that correspond to local expectations. Recent research has probed the determinants of companies' social activities in the local community, 
focusing on the characteristics of the community and the company (Kobeissi and Damanpour 2009) and how local support benefits the firm (Kilkenny, Nalbarte and Besser 1999). The existing research in the area does not particularly consider the individual. However, we propose that corporate community responsibility, particularly in smaller and rural communities, is a fruitful focus when seeking to recognize and understand further how individuals influence and are influenced by CSR. The embeddedness of the individual in various types of social and economic arenas (as owner, manager, or community member) should be more visible in these communities, enabling the identification of the individual dimensions of CSR practices.

The purpose of this article is to improve our understanding of the nature of social responsibility in actual practices and, specifically, the influence of individuals on these processes. We take the individual and the local community as our points of departure to analyse and add insights into how the embeddedness of individuals in local cultures translates into corporate community responsibility.

CSR research has to a great extent concentrated on large firms (Lepoutre and Heene 2006; Worthington, Ram, and Jones 2006) and on the global community perspective, characterized by larger firms' commitment to environmental issues, human rights (including child labour), and approach to business in less developed countries (Sahlin-Andersson 2006). In view of that, the current article also seeks to contribute by adding to the research on community-oriented responsibility (Besser and Miller 2004; Besser, Miller, and Perkins 2006; Boehm 2005; Hall 2006; Kobeissi and Damanpour 2009) and small firm CSR (Blombäck and Wigren 2009; Burton and Goldsby 2009; Murillo and Lozano 2006; Spence 2007).

\section{Approach}


The theory of embeddedness provides a basis for CSR analyses that explore how firms' practices are influenced by interpersonal relations and networks of interaction. As owners and managers are often part of different local arenas, business- and non-business-related, we maintain that the notion of embeddedness (Granovetter 1985; Uzzi 1997) is especially useful for developing knowledge about the nature and processes of corporate community responsibility. To enable a thorough elaboration of how individual embeddedness influences CSR, we are also inspired by interpretive accounting studies (Jönsson and Macintosh 1997), which ask the question 'who is accounting to whom over what?' This framework helps to reveal the ways in which individuals are held responsible, or accept responsibility, on behalf of whom, and why.

The article is structured as follows. First, a theoretical framework emphasizing the importance of embeddedness, accountability, and membership to understanding CSR is provided. Thereafter, we present four empirical stories to illustrate how owner-managers and managers are held responsible or perceive themselves as responsible in relation to the actors and networks in the local community and how this influences corporate community responsibility in practice. We end with conclusions and ideas for further research.

\section{Embeddedness}

The conception of embeddedness reflects the 'contingent nature of economic action with respect to cognition, social structure, institutions, and culture' (Uzzi 1997, 36). In essence, the phrase explains that firm behaviour (economic activity) can only be fully understood if we recognize that firms exist in the midst of social networks, which influence them. The concept was introduced in the first part of the twentieth century but gained wider recognition as a result of the work of Granovetter $(1985,1992)$, which emphasizes the relational aspect of economic action, 
taking place within networks of interpersonal relations. He explains that people's attempts at purposeful action are embedded in 'concrete, ongoing systems of social relations' (Granovetter 1985, 487), and emphasizes that this does not necessarily make decisions less rational but causes them to be based on a range of situational factors. In other words, embeddedness contextualizes economic activity in ongoing patterns of social relations. Currently, drawing on the work of $\mathrm{Zu}$ kin and DiMaggio (1990), researchers distinguish between four types of embeddedness: structural, cognitive, cultural, and political embeddedness.

Structural embeddedness primarily explains how the architecture of network ties and material exchange influences economic activity. The viewpoints here include the connectedness, information access, and relational quality among network members (Burt 1992; Granovetter 1992). One important point of structural embeddedness is that it reveals how a focus on dyads is insufficient to explain the activities within that particular dyad. Instead, the structural embeddedness suggests that the economic activity of each actor is influenced by his or her position in the network as a whole (Granovetter 1992). Cognitive embeddedness concerns the cognitive similarities among actors, for example in terms of how they perceive the environment and room for action. It implies that 'the ways in which the structured regularities of mental processes limit the exercise of economic reasoning' (Zukin and DiMaggio, 1990, p. 15-16). This is connected to the notion of bounded rationality, which explains how the rationality assumed in neoclassical economics cannot be found since business decisions are always taken with limited information and room for manoeuvre. Cultural embeddedness represents the shared collective understanding, beliefs, and values that shape economic aims and strategies. In essence, cultural embeddedness is displayed as firms comply with generally accepted norms, values, and beliefs. Finally, political embeddedness represents the institutional framework of economic action, including the political 
and legal issues that limit economic power and incentives. Political embeddedness shows, for example, when companies adhere to industry and national regulations.

\section{Embeddedness as a means to understand CSR}

The classification of embeddedness is useful for analyses of social influences and interdependence. With regard to the nature of CSR, which by definition represents the realization of business organizations as engrained parts of society, it has the potential to reveal important dimensions. For one thing, CSR can be seen as an outcome of the different types of embeddedness - network position (structural), conforming to norms and values (cultural), acting in view of bounded rationality (cognitive), and conforming to institutional agendas (political). So far, though, only a few scholars have specifically adapted an embeddedness framework to reveal and analyse CSR (e.g. Kilkenny et al. 1999; Zhao forthcoming). Viewing the types of embeddedness from a CSR perspective, they appear relevant in different ways. In this article, we primarily focus on the cognitive and cultural types of embeddedness. These are closely related and clearly tied to a sociological viewpoint of business behavior as they incorporate elements like: institutional environment, norms, and values that guide behaviour . Such elements would be particularly important for understanding how individual actors perceive and relate to responsibility in the local community. They are, however, primarily excluded from the structural and political embeddedness frameworks.

Revisiting the aim of this article, we maintain that embeddedness is particularly central to identify the role of individuals in CSR and to explaining the practice of corporate community relations. In support of this assumption, Besser et al. (2006) find that highly networked firms show a higher propensity to provide support for their community. For locally oriented companies, the embeddedness in networks is particularly salient as they form 'the basic structure' of the local 
culture (Johannisson 1984, 34), something that local firms must pay attention to in order not to risk their membership and license to operate. In firms that are well rooted in small communities, owner-managers and CEOs are likely to be known as company representatives and inhabitants. They will experience ties to people in networks in the community that cannot easily be distinguished as either 'business' or 'private'. This presents a challenge as the interpersonal relations relevant to business might overlap with those relevant to daily and family life (Johannisson 1992). This raises questions in regard to whether and how individuals are able to distinguish between roles and attached accountabilities. What influence do the multiple roles of individuals in the local community have on firm behaviour?

\section{Accountability and CSR}

The concepts accountability and responsibility are closely related and some writers use them interchangeably (Lindkvist and Llewellyn 2003). Here, accountability refers to the everyday processes of giving, demanding, and receiving accounts (Munro and Mouritsen 1996; Roberts and Scapens 1985): processes related to explicit as well as implicit expectations and demands. In other words, accountability is about explaining and justifying one's actions, which means that it is central to any organizing efforts. A central question in the interpretive studies of accountability is 'who is accounting to whom over what' in different settings (Munro 1996, 16). A basic assumption is that even when the procedures for giving accounts seem tightly and explicitly defined, the processes of accountability can be complex and problematic. With the interpretive approach, corporate responsibility can be seen as an illustration of methods and demands for accountability that are constantly created and recreated rather than static and settled. CSR activities and ac- 
counts are then responses to the efforts of holding individuals or organizations responsible and indicators of who is accounting to whom over what in different organizational settings.

\section{Responsibility, membership, and embeddedness}

To be seen as responsible actors, individuals and organizations must supply (and demand) suitable accounts for each context in which they operate. Solli and Jönsson $(1997,19)$ explain that 'to be competent and trusted means to be able to distinguish between discourses and to perform to expectations in the intended context'. On that note, Munro (1996) discusses inclusion and exclusion of membership as one 'method' of accountability. Simply put, if organizational actors in their role as trusted managers, business partners, and/or colleagues do not comply with the legitimate ways of accountability in a certain context, they run the risk of losing their membership of the particular group of actors to which they subscribe.

This article emphasizes two relevant aspects of membership (Munro 1996). The first is that the social arrangements of membership are never settled. People are constantly engaged in finding out the answer to questions like 'who are you to me?' Munro (1996) explains that since there is always undecidability regarding this question, participants are continuously engaged in identity work to settle such issues. In this process, being held accountable addresses, shapes, and confirms our roles and relations to others and CSR practices can be one means to address accountability. The second aspect is that organizational actors typically have multiple memberships. Managers, for instance, are not only members of the company for which they work. They can also be part of families, groups of friends, neighbourhoods, religious, political, or sports associations, and industry organizations: all networks in which certain values and norms exist (Johannisson and Mønsted 1997). The firm's and individuals' memberships and aspirations to maintain these are potential sources of firm (or economic) behaviour. Thus, in this article we approach 
decisions related to corporate community responsibility as acts of accountability in order to help reveal the role of individuals and interpersonal relations in firm behaviour.

\section{Four Empirical Stories}

Following a number of empirical studies on SMEs, we realized that we had come into contact with several examples of corporate community responsibility. The activities, however, were neither talked about as parts of a CSR strategy nor referred to as corporate community responsibility. Instead, we noted how the respondents talked about their commitment to local communities as if it were given: a responsibility beyond the business rationale. Having conducted a literature review on CSR and SMEs (partly presented in XX and XX 20XX), we started to reflect upon the concept of corporate community responsibility and how it could be understood in light of the theories of interpretative accounting and embeddedness. We revisited the existing empirical data and identified several cases that supported our line of reasoning. Reading the empirical data in the light of corporate community responsibility and CSR, we could identify gaps in the existing theory and how our empirical stories contributed to the development of the field of corporate community responsibility and CSR. Thus, we classify this article as an example of the abductive approach to research (Alvesson and Sköldberg 1994): an approach that has also previously been recognized in CSR research seeking to develop theory by moving between theory and empirical cases (Heumer 2010).

We present four stories from previous research. The stories help us answer the purpose of the article, to improve our understanding of the nature of social responsibility in actual practices and, specifically, the influence of individuals on these processes. They make it possible to display and analyse how individual actors' multiple memberships of networks translate into contextual 
interpretations of responsibility and corporate community involvement. The stories have in common that they mirror the situation in small or medium-sized firms situated in small and rural communities and from each story we are able to distinguish the individual's contemplation about membership of the local community and its connection to the business corporate community responsibility practices; we can thereby learn about the multitude and overlapping of individuals' roles in society.

The first story originates from an ethnographic study including observations, interviews, document analyses, and conversations with numerous business managers in an industrial district (Wigren, 2003); the purpose of the study was to identify the local culture in the district. The second and third stories derive from a qualitative study with a focus on understanding the competitive situation for Swedish casting firms. For the second story, we specifically draw on two semistructured personal interviews with the owner-manager, each interview lasting for approximately one hour. In the third story, we rely specifically on one semi-structured personal interview with an owner who works as the marketing manager, which lasted for approximately ninety minutes. The fourth story originates from a qualitative interview study with a focus on subcontractor brands (Blombäck, 2005). The story specifically reflects input from three personal interviews with the CEO and two employees (one per interview). The interviews lasted between thirty minutes and two hours.

Our ambition with the four stories is to demonstrate how the embeddedness and overlapping roles of individuals in the local community influence corporate community responsibility practices and accounts. For this reason, we do not provide fully fledged CSR analyses of the companies in question, but focus on illustrative situations or events. The stories are purposely chosen to provide information on different dimensions of overlapping roles and their impact on 
accountability (cf. information-oriented selection of cases as presented by Flyvbjerg, 2006). The first story shows the influence of interpersonal relations and overlapping CSR rationales when a group of actors ascribe responsibility to a larger group of actors. The second story confirms the influence of individual values and interests on CSR as well as the impact of embeddedness in social organizations. The third story shows the overlap of social and economic concerns as the individual's search for belongingness in social networks overlaps with the local demands for corporate community responsibility. The fourth story shows how the scarcity of local embeddedness and individual accountability influences the approach to corporate community responsibility.

To clarify the stories' contribution to our ambition, we rely on the basic question of interpretative accounting theory - 'who is accounting to whom over what?' In the light of this question, we identify the link between individuals' memberships and their firm's commitment to supporting the community, that is, how the embeddedness of individuals leads to certain firm behaviour. In other words, we approach corporate community responsibility as accounts that reflect embeddedness.

\section{Story one - The local business network: Building an inn}

The empirical scene for this story is a manufacturing industrial district in the south-west of Sweden. In the district local business owner-managers, in alternative ways, support, and are supposed to support, the local community. There is an ongoing dialogue regarding external ownership and how an increased number of externally owned firms might influence the local culture in the district, according to local owner-managers, in a negative way. When locals stress external ownership as a threat to the local culture, they do not necessarily only mean business life but also life outside the firm in general. One local owner-manager expresses that those running a firm and 
living in the municipality are expected to be the janitors in the class, ensuring that all the managers do take on responsibility for the local community. However, the locals should also be visionary and make sure that the community develops.

The business owner-managers in town decided to invest in a local inn, as the town did not host any lunch restaurants and many noticed the lack. The decision to restore a local inn was made during a monthly breakfast meeting arranged by the local trade association. It was decided that local firms would sponsor the project, and the amount of money they would invest would depend on the number of employees in each firm. Most of the privately owned firms agreed to this. It was, however, harder to convince the managers of the externally owned firms since their parent companies did not see the importance of investing in a local inn. A local owner-manager says:

For me it was easy, but an owner-manager for an externally owned company has problems explaining to the executive board that the company should invest money in a local hotel [inn], but we have managed. All are in, every firm.

To put it simply, it is hard to argue for the return on such an investment. A local meeting place for networking activities is not enough. So, if this was a rather small decision for the privately owned firms, the opposite was true for the externally owned ones. The firms with spread or non-local ownership had to make the decision during their board meetings. The CEO of one of the major externally owned firms in town reports that when he did not decide to sponsor the inn immediately he was called upon by one of the locals, by whom he was told that it would be wise for the firm to decide to sponsor the inn. When talking about the inn, a local business ownermanager uses words such as:

Everybody shares a special feeling for [the inn], everybody supports it and feels a sense of belonging to the project. 
The story shows how business owner-managers took on responsibility 'for the local community' when they initiated the local inn. To be considered a responsible business partner in this context, participation in such a project was expected. The local business owner-managers expected their colleagues in the 'externally' owned firms to engage in the processes and take on the same responsibility. For the managers of the externally owned firms, however, it was hard to defend this project to the company group management. This made the local owner-managers even more skeptical towards commuting managers in general and towards 'external' ownership in particular. The local business owner-managers saw business managers as responsible for the daily life in the community, for the business society, and for the other inhabitants in the society. The action taken by the business owner-managers aimed to obstruct the disarmament of the society. Their aim was to rescue the local community; they fought for the survival of the society as they knew it.

Regarding the question 'who is accounting to whom over what?', we find in the story that all the owner-managers and CEOs are held responsible for developing the municipality. They are held responsible in relation to each other and in relation to the municipality and its development. The owner-managers are socially embedded in the society and shoulder the responsibility for the development of the local community. As they are both owner-managers and community members their roles overlap.

\section{Story two - Tillage casting: Investing in the locals' health}

Mr B has been involved in manufacturing in Tillage since 1965. Tillage is a 'living' community in the south of Sweden, which has approximately 3000 inhabitants, schools, stores, and sports clubs with several hundred active members. The village also has a dynamic business community, 
including several manufacturing industries and subcontracting and retailing firms. The amount of firms located in the community requires firms also to employ people from surrounding villages and a nearby town. Mr B has lived in the village for a long time and in 1981 he acquired a casting firm together with a friend. Since 1998 he has been the sole owner and CEO; his wife and daughter also live in the village and work in the business.

Given the opportunity to reflect on CSR, Mr B primarily focuses on the importance of maintaining a workforce that is healthy and understands the importance of nutritious food and exercise. He has previously employed a lifestyle coach to support employee development. His arguments represent CSR that focuses on the actors inside the firm. Discussing the company's connections to the local community, Mr B displays a strong interest in sponsoring sports-related activities.

Well, it's probably because I'm interested in sports myself. It might be the reason. But I'm involved in the [local] sport association myself and I notice the effort those leaders put in. I believe it's good to support sport associations. And, as a result you also get a good reputation, of course. But I don't think, we don't get that many customers by sponsoring the sport association ...

When questioned further concerning the importance of a positive reputation and whether local sponsoring is a planned effort to gain that reputation, he declares, with some emphasis:

No, it's not that important. It's more a question of wanting to help, financially. I don't believe we gain so much from it. It's not something that, well, [it's] not a strategy that we have.

In further elaboration his commitment to sports and belief in the importance of sports for youth becomes clear. He strongly criticizes the schools' lack of responsibility for children's health. His reflections imply that he really holds someone else accountable for this issue. However, as they do not accept accountability, respond, or behave in a way he considers responsible, he took on the responsibility. 
This story reveals how incongruence in accountability can influence corporate community relations. The owner-manager perceives that the school system does not deliver according to its accountability. It seems that the CEO's personal interests and passions function as a guide for the company's involvement in the surrounding society. His role as the owner-manager and CEO is mixed with his role as a community member and an individual who believes that exercise is essential for a good life. The projects considered in the illustration relate to health-oriented activities in the community, which can have short- and long-term effects for the involved individuals and for the community at large. Correspondingly, the owner-manager does not describe these activities in view of the business.

Regarding the question 'who is accounting to whom over what?', we find in this story that it is the owner-manager who holds himself responsible for the health and well-being of the company's employees and the local youth. The CEO is clearly well embedded in the society and feels a strong membership of the local sports associations in which he is active. While he does not express that there are demands for his commitment from this local arena, we cannot disregard that the activities might be explained by cultural embeddedness and the expectations placed on local firms to engage in society. Essentially, though, the story clarifies the social and economic overlapping of individual roles and how an individual with power over firm resources lets personal values and interests guide the firm's orientation towards CSR.

\section{Story three - Ironcycle: Coping with local traditions}

Since September 2005, Mr M and his partner Mr N have been the new owners of Ironcycle, a firm that has operated in the same village since 1906. The village has about 500 inhabitants but is geographically close to a township with approximately 5000 inhabitants. Mr M and Mr N have 
no previous connections to the area but since the acquisition they have lived in the village from Monday to Friday. A discussion about CSR was arranged with Mr M.

Due to the embedded nature of the firm and its heritage, and the necessity to maintain a workforce, Mr M explains that it is difficult to separate the management of Ironcycle from what happens in the community.

... This firm has been around for a hundred years so it's an institution. Everyone knows about it and, well, almost everyone has some kind of relation to it. And of course, we have to behave in the community. Because we want manpower, we want a good reputation. We have to cooperate with the inhabitants and surrounding firms and so on. We cannot behave badly.

When he elaborates further on why CSR is necessary he reveals that the new owners perceive pressure from the local inhabitants to perform and manage the firm in a way that is consistent with the history and business culture of the community.

Well, if one wants to remain long term one has to have a good reputation. There's no doubt about it. You have to have employees who feel safe and so forth. And of course, in a very small place, like this, everyone is watching you. And especially when outsiders like myself and $\mathrm{Mr} \mathrm{N}$ turn up. Everyone keeps close track so you don't come here, make some trouble, and then take off with the money.

The pressure from and dependence on the local society is also apparent when $\mathrm{Mr} \mathrm{M}$ concludes that the business cannot be moved and how this fact influences the actions they decide to take in the community.

Unless you have the idea to move production to China or something, which is not in our strategy since manufacturing in this place is also part of the brand. So, of course we have to take our responsibility here. Regardless of whether we want to or not, we are forced to do it. So, the decision is very easy ... 
Then again, Mr M also suggests that the pressure from society will affect a firm differently if the owners do not live in the community in which the firm is situated. He argues that it will be easier to ignore or make decisions that affect the community if you do not have to face the people in question, concluding that:

Well, Mr N and myself live in the community where the company and the plant exist. And a social pressure does appear.

Still, Mr M explains that although such responsibilities are important, they are not the chief aim of the firm. Hence, if forced to make a choice, the survival of the firm will always be the most important. However, he also concludes that:

$\ldots$ if there is no conflict, or if it's a minor operation, then of course you have to take a responsibility. And most often the two go hand in hand with each other. If you don't take it [the social responsibility], the company will be affected [in a negative way].

In this story we learn how corporate social responsiveness towards the local community can be traced back to the business objectives as well as the owners' private concerns. It shows that the new owner-manager, who is not yet an embedded member of the community, makes an effort to identify and understand the cultural embeddedness of the firm and meet the expectations, rather than trying to avoid such responsibilities. In sum, accounts are demanded by the society that the new owners understand and maintain the importance of the firm's local presence. The CEO recognizes this and also accepts that taking social responsibility is part of running this particular firm successfully. From the corporation's point of view, the local community activities (sponsoring and arranging company events) are justified by the company's need to maintain a good reputation among its employees (current and potential) and to fulfil the current expectations among the community members. 
Regarding the question 'who is accounting to whom over what?', we find in the story that it is the owner-managers who are held responsible for responding to locals' and current employees' expectations of continued community support, e.g. sponsoring sports and arranging community events. The responsibility is in relation to the local community and to the employees. The story portrays how the previous owner was embedded in the local community and how the people now expect the new owners to behave in the same way as the former owner.

\section{Story four - Oakley: The non-local's perspectives on sponsoring}

Oakley has manufactured steel and aluminium parts in the same village since 1970. In 2001 the firm's ownership changed from private and local to an international investment company. The firm is now experiencing its first non-resident CEO, who does not live in the community but commutes from a nearby city. Most employees live in the community, which depends on the widespread presence of manufacturing industries for occupation, primarily with a focus on wood and metal. The village has approximately 1500 inhabitants but is within easy reach of several larger towns.

In regard to financial support for local organizations, Oakley's CEO has taken the decision that this must always be connected to the interests of one or several employees. The reason for this policy is to avoid giving away money according to subjective criteria. Explaining the underlying reason for sponsoring, he says:

$[\ldots]$ it's mostly to be nice. I don't believe we sell one extra item because we have a billboard up by the race tracks.

The sponsoring activities are clearly not part of a commercial strategy. However, he also recognizes that they might provide benefits in the nearby community: 
... it might have an impact on our reputation here in town though. And I think that is not the least

important. We have said that if possible we shall have a good reputation in town. It's important when we are looking for people [employees] ...

This story shows how corporate community relations can be seen primarily as a matter of business strategy. While the CEO admits that some activities are related to the local culture, his rationale for the activities is focused on the business logic. Recognizing that the firm is held accountable by employees and community members, he provides what they ask for, to some extent in order not to jeopardize the company's reputation and to maintain favourable images among the employees (current and future) and local suppliers. The interviews with employees confirm that there are expectations and demands on the CEO to continue the firm's previous commitment to the community. Still, the CEO's accounts related to corporate community responsibility suggest that he approaches decisions about corporate community responsibility primarily based on his membership of the management team, which is accountable to the board and owners of the business. The approach is primarily explained by the economic domain of CSR and indicates an instrumental approach, whereby corporate community responsibility is a means to a business end (cf. Jones 1995; Schwartz and Carroll 2003).

Regarding the question 'who is accounting to whom, over what?', we find in this story that the CEO is held responsible for the firm's financial support of local sport associations. The actors demanding accounts in this case are the employees and the local community. The CEO makes sure that the level of support is within the expectations and thereby accounts for the firm's community responsibility. At the same time, his concern for the economic and business rationale related to these activities can be interpreted as part of accounting towards the board of directors, for the firm's financial result. In summary, the CEO himself lacks a sense of local embeddedness, 
but since the firm has a long history in the village and is seen as embedded, he is still held responsible by the local employees for ensuring that the company follows the local culture. We suggest that the CEO as an individual is rather influenced by cognitive embeddedness, related to his membership, in the role of external CEO, of the conglomerate owner. As a result, the corporate community responsibility is kept to a minimum.

\section{Analysis of the four stories}

To develop our findings we continue our analysis of the stories by focusing on three themes: closeness to local stakeholders, the individual self, and the presence of overlapping rationales.

\section{Closeness to local stakeholders}

The stories indicate some important differences between employed CEOs and CEOs who are also owners and local inhabitants. While both types of CEO will be held accountable in the local arena, the stories imply that their accounts of responsibility and whom they perceive themselves as accountable to can differ. Primarily, owner-managers are essentially in the position that they can make any decision they like regarding the spending of the firm's resources. Employed CEOs, on the other hand, have to consider their role as having been hired to carry out a certain job, which involves accounting for the financial result to the board of directors and/or owners. Also, CEOs who are not clearly part of the community, perhaps having recently moved there or commuting daily, are bound to experience less overlap between their roles and their responsibilities. While they might be part of several business-oriented arenas (e.g. their own firm as well as a local business network) they will not fulfill the role of a local community member. Still, given that culture develops over time in the interaction among individuals, the non-local CEOs' cultural and cogni- 
tive embeddedness will differ from that of the local CEOs. These conceivable differences in embeddedness are particularly exposed in stories one and four.

In the first story, a group of local owner-managers hold all other CEOs accountable but some of these CEOs do not clearly identify their responsibility. The first group had strong cognitive and cultural embeddedness, which made them suggest that taking responsibility for the local inn was the right thing to do. As they ascribed this responsibility to all local firms, the difference in embeddedness and, thus, in the willingness to accept this responsibility was, however, apparent. The locally embedded owner-managers saw themselves as being accountable towards each other for the local community's maintenance and accepted the responsibility. Thanks to the governance structure of these firms $(\mathrm{CEO}=$ owner $)$, they could also accept the responsibility without further ado. Their multiple roles as CEOs and members of the community and business network made it virtually impossible for them to neglect participation. Being culturally and cognitively embedded, they also identified strongly with the local norms and values. The non-local CEOs of externally owned firms, on the other hand, did not immediately recognize themselves as accountable for the inn. One interpretation of that is that they were instinctively closer to the norms and values of the parent company, which included more complexity in regard to decisions about spending money on non-business activities. That is, they were also embedded, but in a different context. Similarly, in story four, we portrayed how the external CEO was not as convinced as the employees about the necessity of continuing strong commitment to the local community.

Also related to the closeness of stakeholders, the stories highlight that perceived membership and aspiration to maintain membership of local networks influence the translation of corporate community responsibility (stories one, two, and three). The third story is particularly illustrative, showing how the new owner-managers attempt to decipher the culture and do things for the 
community, to gain legitimacy in the long term. The reason is that they plan to live in the community, close to a range of business and non-business actors, and therefore aspire to become members of the local community. In this case, the intention to stay close to the local stakeholders in the long run, as individual community members and as business owners, was one determinant of the firm's approach to corporate community relations.

\section{The individual self}

The four stories portray the engagement of the owner-managers with the local communities. The stories hint in the direction that owner-managers who live in the local communities take on responsibility for the development of the local communities beyond the firms. One explanation could be that those firms are more networked, as their owner-managers participate in several local arenas. Furthermore, their roles as business persons overlap with their other roles (e.g. being neighbours, church members, members of the same sport associations, etc.). Previous research shows that highly networked firms show a higher propensity to provide support for their communities (Besser et al. 2006), and that in small local communities reciprocity is developed between the owner-managers and the community (Kilkenny et al. 1999). This study adds to this ongoing dialogue and stresses that since the roles are overlapping it is not obvious if the owner-managers take on the responsibilities as owner-managers or as community members. Responding to the expectations in the business network can, thus, be interpreted as a result of the firm's enlightened self-interest (Besser and Miller 2004) and as an indication of the individual's enlightened selfinterest. Furthermore, it might not even be an expectation from someone else, as is portrayed in the second story when the actions taken are not connected to expectations from employees or the local community. Rather, this story exemplifies the transfer of an individual's passion for health, sports, and well-being to corporate-level activities (cf. Burton and Goldsby 2009; Hemingway 
and Maclagan 2004). In the first story, the reason for sponsoring the inn might very well be twofold: for the owner-managers, having an inn to visit is probably important in the role of a manager as well as being a service that they will appreciate having access to during leisure time with family and friends.

The four empirical stories exemplify the influence of the individual on CSR. They show how owner-managers accept responsibility for matters external to the firm and how they respond to expectations related to their various memberships through corporate local responsibility. They largely decide on the CSR activities that the firms will conduct. Rather than pressure from geographically distant or anonymous actors and stakeholders, the choice of CSR activities is influenced by the owner-managers' individual values and relationships with actors at close range. The interpersonal relations in business and in daily life might overlap (Johannisson 1992), as well as the interests that are in line with the operation of the business possibly overlapping with the interests of or daily life in the community. In cases when there is no obvious overlap, the ownermanagers, in line with the stories, act in their own interests - and in most of the cases it is possible to identify a rationale for why the owner-manager and the firm invest in the specific corporate community relations that they do. The stories hint that it is difficult to distinguish between the roles and the attached accountabilities. The roles of the individual influence the behaviour of the firm, or more correctly the behaviour of the owner-manager as the firm is not an entity that acts on its own.

\section{Overlapping rationales}

In view of Schwartz and Carroll's (2003) categorization of corporate responsibility domains (economic, legal, ethical), in the stories we interpret that the respondents relate to the ethical and economic dimensions to legitimize the corporate community responsibility that they take on. Re- 
garding the economic domain, the stories relate to how the activities strengthen the brands of the companies in the local communities among current and potential employees and among others. Alternatively, the activities can be related to local development, from which the communities in the long run gain economically, as in the first case about the inn (to attract outsiders to stay and eat in the community), or in the second about schools' lack of responsibility for children's health, i.e. the future of the community. There are underlying economic rationales that can be interpreted in all of the stories. In the second story, for example, even if the owner-manager does not relate his investments in health and well-being to fewer spells of sick leave and a more efficient group of employees, his action can be related to an economic rationale, as we know that healthy and happy employees tend to perform better. However, an economic rationale might very well overlap with an ethical rationale. That is to say that the activities can be attributed to more than one rationale.

Defining activities as belonging to the ethical domain is, however, more difficult, as ethical behaviour is contextually defined. All the stories, in one way or another, suggest that the owner-managers behave as they do because they think and interpret as others in the community expect them to do, or they do it because they just want to give something back. We read our stories as expressions of cognitive and cultural embeddedness, to help explain why the ownermanagers and managers do what they do. The local owner-managers perceive the environment and room for action in a certain way because of their cognitive embeddedness, and they have a shared collective understanding, beliefs, and values that shape their aims and strategies, i.e. their cultural embeddedness.

As discussed above, though, the stories reveal that individual/private concerns are also one factor in decision-making. In response to this, we suggest that the commonly employed, 
three-dimensional construct of CSR (Schwartz and Carroll 2003) needs amendment. Our findings support previous works that identify the individual in CSR (Burton and Goldsby 2009; Hemingway and Maclagan 2004), implying that we must also include individuals' passions to understand CSR. In addition to their findings, however, our stories assist in showing that the multiple and overlapping roles of individuals make it difficult to distinguish whether certain decisions are based on either the individual or the firm's concern. Often, two rationales can be found for the use of firm resources in the community: one that legitimizes it from a business point of view (economic, legal, and/or ethical) and one that explains it by enlightened self-interest. To take into account this individual dimension, a fourth domain should be added to the construct. Similar to the other three domains, it would, more often than not, overlap with the others.

\section{Conclusion}

The purpose of this article was to shed light on the nature of responsibility, how it operates, and who is responsible. Specifically our aim was to improve understanding of how individuals influence these processes. Much previous research describes the firm level and how decisions on CSR are made in perspective of demands and perceptions related to the firm's responsibility to fulfill legal, economic and ethical business rationales. The research is still scarce, though, in regards to how these rationales are translated into corporate community responsibility. This paper displays and analyses how individual actors' relationships with local arenas translate into contextual interpretations of responsibility and corporate community involvement in the four stories above. In view of ideas from interpretive accounting and the theory of embeddedness our study confirms that discussions of CSR that focus on the firm as the unit of analysis and do not 
take into account multiple levels of analysis only solve one part of the puzzle. Decisions and actions are ultimately executed by individuals who hold specific positions in the firm.

In our illustrations the individuals are owner-managers and CEOs, which implies that their role involves executing decisions and taking action. The stories display how individual actors' contextual translations of responsibility influence corporate community relations. That is, the stories exemplify how, depending on the individuals' relationships with local arenas, the corporate community responsibility is reasoned and develops differently. The study also indicates the importance of the theory of embeddedness to understanding the topic of corporate responsibility and, specifically, community relations. The stories show that notions of how and to whom firms, their owners, and their managers are accountable shape the orientation of corporate community responsibility. Activities in the name of the firm do not simply originate from concerns for or rationales related to the business operations. Similarly, the activities are not easily defined as being solely related to the individual's private concerns or personal values. In the private firm, in a local community context, the concerns of the individual in charge and the corporation are likely to overlap (cf. the outline of individual or corporate locus of responsibility by Hemingway and Maclagan 2004, 34). As researchers we have so far searched for the rationale behind CSR primarily based on the company as the unit of analysis. The current study implies that, to understand more fully the antecedents of certain corporate community behaviour, we must take into account the translations of responsibility by owner-managers and managers, given that they can have stakes in the firm as well as in various local networks. Our findings are summarized in a conceptual model (figure 1).

[Insert figure about here] 
The model clarifies our contribution to extant research in two steps. First, it emphasizes the connection between the individual's embededdness in the local community and the firm's corporate community responsibility. The embededdness implies that the individual ownermanagers are not only close to the local community but actually part of it. This means that they are familiar with local norms and perceive expectations and, consequently, can determine the room for action. Secondly, the model clarifies that we find two dimensions of this individual influence on community responsibility; one pertaining to business rationale and one pertaining to the individual's self-interest. This points at how the inherent overlap of individual and firm ultimately also creates an overlap of interests. A significant finding is the difficulty of distinguishing whether decisions are made on account of the individual's or the firm's concern. The conceptual model means to capture this fact that two logics can be found for the use of firm resources in the community: one that legitimizes it from a business point of view (economic and/or ethical) and one that explains it with the individual manager's enlightened self-interest. Thanks to their closeness with community stakeholders and simultaneous power over the firm's resources, individuals can also make decisions pertaining to their own interests, which are executed in the form of local CSR.

This study supports Aguilera et al.'s (2007) and Wood's (1991) arguments that corporate responsibility needs to be studied at different levels. Organizational actors are held accountable as formal spokespersons of a corporation and as members of other groups, for example the local group of responsible owner-managers. Since the illustrations show that these memberships are never completely settled, we agree with Lindqvist and Llewellyn's (2003) call for researchers to pay more attention to the mixture of individual and communal responsibilities among reflecting 
actors. The analysis strengthens the proposition that particular corporate cultures and frameworks of relationships strongly influence the interpretation and translation of corporate responsibility (Murillo and Lozano 2006, 227).

The current study also contributes to Wood's (1991) call for elaboration on the individual's responsibility. The four stories demonstrate that, to comprehend more fully the occurrence of responsibility and activities, it is not sufficient to distinguish between the levels of individual, firm, and institution. At each of these levels, the actions undertaken can be explained differently depending on which roles or memberships are considered. An overlap of the private, public, and business spheres of life denotes complexity, which makes it difficult to distinguish who is actually held responsible. Furthermore, as companies are comprised of individuals, they, by definition, cannot act. It is the people, like owner-managers and CEOs, who represent the action. To fulfill Wood's wish that CSR needs to be studied at different levels, we propose that the 'micro-level' connections within groups are important for understanding networks and networking, and the macro-level connections between groups. Our first story, for example, shows how groups of owner-managers and employed managers relate to CSR activities, and how the dynamics between the groups and the local culture influence the action.

Interpreting CSR by incorporating individuals' narratives and perceptions of accountability and responsibility reveals a complexity of CSR that is often overlooked in descriptions of the phenomenon. CSR activities should not be taken out of context. To be understood, they must be related to the current views on responsible business management in the settings at hand and previous accounts, and analysed in the light of the existing accountability ties. In line with the interpretive perspective on accountability, the illustrations also show how the history of CSR accounts 
in particular contexts affect stakeholders' notions of what counts as acceptable business performance in terms of corporate responsibility (cf. Laughlin 1996; Roberts 1991, 1996).

As a consequence of the multiple roles and levels of responsibility that the current article reveals, it is necessary to consider further the notion of corporate responsibility as something voluntary (cf. the definition by the Commission of the European Communities 2001; Longo, Mura, and Bonoli 2005). By analysing the content of corporate responsibility and the activities considered through accountability and multiple memberships, the very framing of such a statement is questioned. To some extent, organizational actors might choose the groups of which they strive for membership, but, as the current illustrations display, they alone cannot set or even negotiate the rules on how to act and account for their actions within these groups. In line with Carroll's (1998) claim, the corporations' 'citizenship' can be interpreted in several ways as a response to expectations rather than something firms do for legal or philanthropic reasons.

\section{Limitations and emerging research questions}

One limitation of the current paper relates to the employment of short cases and the restricted empirical material this implies. The illustrations were specifically selected to verify and shed further light on our assumption that embeddedness is central to identify the role of individuals in CSR and explain the practice of corporate community relation. This type of empirical selection, however, prompts reflection about validity. As the underlying empirical material was collected with focus on other research questions the information at hand is limited with regard to comprehensive accounts of the complexity in CSR. To validate our findings further research is necessary; in part to verify that our identified themes and conclusions reflect an occurring pattern of behavior but also to explore additional ones. 
The specific phenomenon that we investigate in this paper is more likely to appear in smaller societies - where the individual owner and/or manager also takes part in non-business activities as a community member but is still recognized as the owner and/or manager of a business. It can probably be identified in urban contexts too, but as it is possible to be more anonymous there it might be more difficult to identify. Nevertheless, the current findings do translate into relevant research questions also in urban and highly international business contexts. As firms in these contexts construct systems and procedures for CSR reporting they need to ensure that they respond in a relevant way to maintain accountability. Multinational companies face a much wider and more complex arena than the businesses illustrated in this paper. It should be further relevant to study how these global firms manage and respond to the multiple local and global settings in which they are held accountable and what strategies exist to translate and eventually balance the meaning of responsible action in each. Who is accounting to whom over what in the many local contexts within the global responsible (or irresponsible) companies? Which official translations of responsibility meet resistance in the local contexts and which corporate actions in the name of responsibility do we yet know little about? Is the meaning and translation of corporate responsibility as one-sided as the official CSR reports indicate? As suggested in previous research, these questions need to be put forward while still directing attention to the individual agent (Ashman and Winstanley 2007; Balmer, Fukukawa, and Gray 2007a, b; Moore and Spence 2006). Consequently, we recommend that future research should explore how corporate responsibility in small, large, and/or global firms is affected by their local embeddedness and the multifaceted roles of their organizational members. By revealing the embeddedness of individuals in local networks, our findings emphasize an important dimension of CSR and that it is indeed a 
complex socio-economic phenomenon. We suggest that the interpretive studies of accountability offer a promising framework to research the area further. 


\section{List of References}

Aguilera, R.V., Rupp, D.E., C.A. Williams, C.A. and Ganapathi, J. (2007), "Putting the S back in CSR: A multilevel theory of social change in organizations", Academy of Management Review, Vol. 32 No. 3, pp. 836-63.

Altman, B.W. (1999), “Transformed corporate community relations: A management tool for achieving corporate citizenship", Business and Society Review, Vol. 102, No. 1, pp. 4351.

Alvesson, M., and Sköldberg, K. (1994), Tolkning och reflektion: Vetenskapsfilosofi och kvalitativ metod, Studentlitteratur, Lund.

Andriof, J. and McIntosh, M. (2001), "Introduction”, in Jörg Andriof, J. and Malcom McIntosh, M. (Ed.), Perspectives on corporate citizenship, 13-24. Greenleaf Publishing, Sheffield, pp. 13-24.

Ashman, I. and Winstanley, D. (2007), For or against corporate identity? Personification and the problem of moral agency, Journal of Business Ethics, Vol. 76, No. 1, pp. 83-95.

Balmer, J.M.T., Fukukawa, K and Gray, E.R. (2007a), Mapping the interface between corporate identity, ethics and CSR, Journal of Business Ethics, Vol. 76, No. 1, pp. 1-15.

Balmer, J.M.T., Fukukawa, K and Gray. E.R. (2007b), The nature and management of ethical corporate identity: A commentary on corporate identity, CSR and ethics, Journal of Business Ethics, Vol. 76, No. 1, pp. 7-15.

Bertels, S. and Peloza, J. (2008), Running just to stand still? Managing CSR reputation in an era of ratcheting expectations, Corporate Reputation Review, Vol. 11, No. 1, pp. 56-72. 
Besser, T.L. and Miller, N.J. (2004), The risks of enlightened self-interest: Small businesses and support for community, Business \& Society, Vol. 43, No. 4, pp. 398-425.

Besser, T.L., Miller, N.J and Perkins, R.K. (2006), For the greater good: Business networks and business social responsibility to communities, Entrepreneurship \& Regional Development, Vol. 18, No. 4, pp. 321-39.

Blombäck, A. (2005). Supplier brand image - a catalyst for choice: Expanding the B2B brand discourse by studying the role corporate brand image plays in the selection of subcontractors. JIBS Dissertation Series: Internationella Handelshögskolan, Högskolan i Jönköping, IHH, EMM (Entrepreneurskap, Marknadsföring, Management).

Blombäck, A. \& Wigren, C. (2009), Challenging the importance of size as determinant for CSR activities, Management of Environmental Quality - An International Journal, Vol. 20 No. 3, pp. 255-270.

Boehm, A. (2005), The participation of business in community decision making, Business \& Society, Vol. 44, No. 2, pp. 144-77.

Burt, R. (1992), Structural holes: The social structure of competition, Harvard University Press, Cambridge.

Burton, B.K., and Goldsby, M. (2009), CSR orientation, goals, and behavior: A study of small business owners, Business \& Society, Vol. 48, No. 1, pp. 88-104.

Carroll, A.B. (1998), The four faces of corporate citizenship, Business and Society Review, No. 100/101, pp. 1-7.

Commission of the European Communities. (2001), Green paper - Promoting a European framework for CSR, Commission of the European Communities, Brussels.

Flyvbjerg, B. (2006), Five Misunderstandings About Case-Study Research, Qualitative Inquiry, Vol. 12, No. 2, pp. 219-245. 
Granovetter, M. (1985), Economic action and social structure: The problem of embeddedness, American Journal of Sociology, Vol. 91, No. 39, pp. 481-510.

Granovetter, M. (1992), Economic institutions as social constructions: A framework for analysis. Acta Sociologica, Vol. 35, No. 1, pp. 3-11.

Griffin, J.J. and Mahon, J.F. (1997), The corporate social performance and corporate financial performance debate - Twenty-five years of incomparable research, Business and Society, Vol. 36, No. 1, pp. 5-31.

Hall, M.R. (2006). Corporate philanthropy and corporate community relations: Measuring relationship-building results, Journal of Public Relations Research, Vol. 18, No. 1, pp. 1-21.

Hemingway, C.A. and Maclagan, P.W. (2004), Managers' personal values as drivers of CSR, Journal of Business Ethics, Vol. 50, No. 1, pp. 33-44.

Huemer, L. (2010). Corporate social responsibility and multinational corporation identity: Norwegian strategies in the Chilean aquaculture industry, Journal of Business Ethics, Vol. 91, pp. 265-77.

Johannisson, B. (1984). A cultural perspective on small business - Local business climate, International Small Business Journal, Vol. 2, No. 4, pp. 32-43.

Johannisson, B. (1992). "Entrepreneurship - The management of ambiguity". Polesie, T. and Johansson I.L (Eds.), Responsibility and accounting - The organizational regulation of boundary conditions, Studentlitteratur, Lund, pp. 155-179.

Johannisson, B., and Mönsted, M. (1997). Contextualizing entrepreneurial networking - The case of Scandinavia, International Studies of Management and Organization, Vol. 27, No. 3, pp. 109-36. 
Johannisson, B., Ramírez-Pasillas, M. and G. Karlsson, G. (2002), The institutional embeddedness of local inter-firm networks: A leverage for business creation, Entrepreneurship and Regional Development, Vol. 14, No. 4, pp. 297-315.

Jones, T. (1995). Instrumental stakeholder theory: A synthesis of ethics and economics, Academy of Management Review, Vol. 20, pp. 404-437.

Jönsson, S. and Macintosh. N. (1997). CATS, RATS and EARS: Making the case for ethnographic accounting research, Accounting, Organizations and Society, Vol. 223, No. 4, pp. $367-86$.

Kilkenny, M., Nalbarte, L. and Besser, T. (1999). Reciprocated community support and small town-small business success, Entrepreneurship and Regional Development, Vol. 11, No. 3, pp. $231-46$.

Kobeissi, N. and Damanpour. F. (2009). Corporate responsiveness to community stakeholders. Effects of contextual and organizational characteristics, Business \& Society, Vol. 48, No. 3, pp. 326-59.

Laughlin, R. (1996). "Principals and higher principals: Accounting for accountability in the caring professions”, Munro, R. and Mouritsen, J. (Eds.), Accountability: Power, ethos and the technologies of managing, International Thomson Business Press, London, pp. 22544.

Lepoutre, J. and Heene, A. (2006). Investigating the impact of firm size on small business social responsibility: A critical review, Journal of Business Ethics, Vol. 67, No. 3, pp. 257-73.

Lindqvist, L. and Llewellyn. S. (2003). Accountability, responsibility and organization, Scandinavian Journal of Management, Vol. 19, No. 2, pp. 251-73. 
Logsdon, J.M. and Wood, D.J. (2002). Business citizenship: From domestic to global level of analysis, Business Ethics Quarterly, Vol. 12, No. 2, pp. 155-87.

Longo, M., Mura, M. and Bonoli, A. (2005). CSR and corporate performance: The case of Italian SMEs, Corporate Governance, Vol. 5, No. 4, pp. 28-42.

Makni, R., Francoeur, C. and Bellavance, F. (2009). Causality between corporate social performance and financial performance: Evidence from Canadian firms, Journal of Business Ethics, Vol. 89, No. 3, pp. 409-22.

Margolis, J.D. and Walsh, J.P. (2003). Misery loves companies: Rethinking social initiatives by business, Administrative Science Quarterly, Vol. 48, No. 2, pp. 268-305.

Marz, J.W., Powers, T.L. and Queisser, T. (2003). Corporate and individual influences on managers' social orientation, Journal of Business Ethics, Vol. 46, No. 1, pp. 1-11.

Moore, G. (2001). Corporate social and financial performance: An investigation in the U.K. supermarket industry, Journal of Business Ethics, Vol. 34, No. 3-4, pp. 299-315.

Moore, G., and Spence, L. (2006). Editorial: Responsibility and small business, Journal of Business Ethics, Vol. 67, No. 3, pp. 219-36.

Munro, R. (1996). “Alignment and identity work: The study of accounts and accountability”, Munro, R. and Mouritsen, J. (Eds.), Accountability: Power, ethos and the technologies of managing, International Thomson Business Press, London, pp. 1-19.

Munro, R. and J. Mouritsen. (1996). Accountability: Power, ethos and the technologies of managing, International Thomson Business Press, London.

Murillo, D. and Lozano, J.M. (2006). SMEs and CSR: An approach to CSR in their own words, Journal of Business Ethics, Vol. 67, No. 3, pp. 305-16. 
Preuss, L. (2009). Ethical sourcing codes of large UK-based corporations: Prevalence, content, limitations, Journal of Business Ethics, Vol. 88, No. 4, pp. 735-47.

Roberts, J. (1991). The possibilities of accounting, Accounting, Organizations and Society, Vol. 16, No. 4, pp. 355-68.

Roberts, J. (1996) "From discipline to dialogue: Individualizing and socializing forms of accountability", Munro, R. and Mouritsen, J. (Eds.) Accountability: Power, ethos and the technologies of managing, International Thomson Business Press, London, pp. 40-61.

Roberts, J. and Scapens, R. (1985). Accounting systems and systems of accountability, Accounting, Organizations and Society, Vol. 10, No. 4, pp. 443-56.

Sahlin-Andersson, K. (2006). CSR: A trend and a movement, but of what and for what? Corporate Governance, Vol. 6, No. 5, pp. 595-608.

Schwartz, M.S., and Carroll, A.B. (2003). CSR: A three-domain approach, Business Ethics Quarterly, Vol. 13, No. 4, pp. 503-30.

Solli, R. and Jönsson, S. (1997). Housekeeping? Yes, but which house? Meaning and accounting context - A case study, Scandinavian Journal of Management, Vol. 13, No. 1, pp. 19-38.

Spence, L.J. (2007). CSR and small business in a European policy context: The five 'C's of CSR and small business research agenda 2007, Business and Society Review, Vol. 112, No. 4, pp. 533-52.

Sweeney, L. and Coughlan. J. (2008). Do different industries report CSR differently? An investigation through the lens of stakeholder theory, Journal of Marketing Communications, Vol. 14, No. 2, pp. 113-24.

Uzzi, B. (1997). Social structure and competition in interfirm networks: The paradox of embeddedness, Administrative Science Quarterly, Vol. 42, No. 1, pp. 35-67. 
Valor, C. (2005). Towards social responsibility and corporate citizenship: Towards corporate accountability, Business and Society Review, Vol. 110, No. 2, pp. 191-212.

Whitehouse, L. (2006). Corporate social responsibility: Views from the frontline, Journal of Business Ethics, Vol. 63, No. 3, pp. 279-96.

Wigren, C. (2003). The Spirit of Gnosjö: The Grand narrative and Beyond, Doctoral Dissertation, Jönköping International Business School, Jönköping, Sweden.

Wood, D. (1991). Corporate social performance revisited, Academy of Management Review, Vol. 16, No. 4, pp. 691-718.

Worthington, I., Ram, M. and Jones, T. (2006). Exploring CSR in the U.K. Asian small business community, Journal of Business Ethics, Vol. 67, No. 2, pp. 201-217.

Zhao, M. (forthcoming). CSR-based political legitimacy strategy: Managing the state by doing good in China and Russia, Journal of Business Ethics.

Zukin, S., and DiMaggio, P. (1990). Structures of capital: The social organization of the economy, Cambridge University Press, New York. 


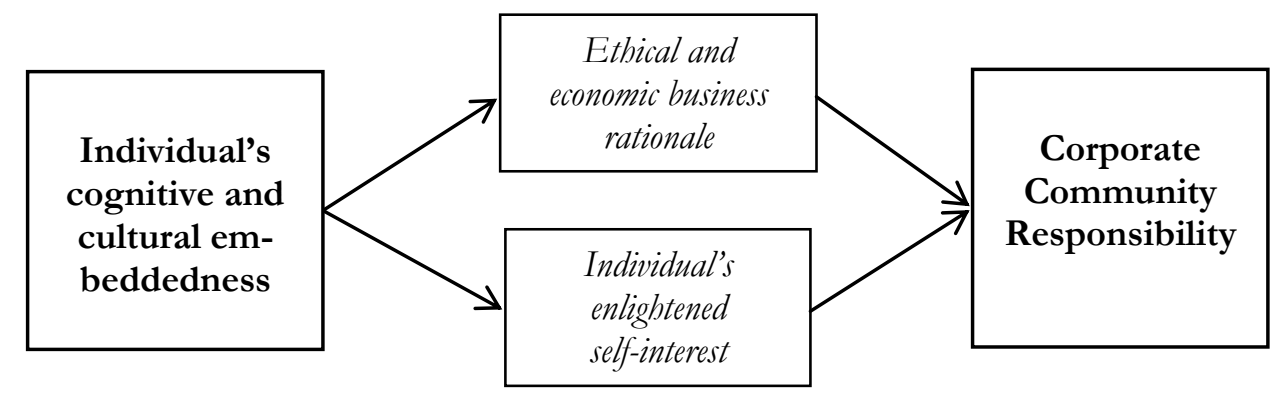

Figure 1: Conceptualizing corporate community responsibility; the role of individual embeddedness 